\title{
Gleb Tsipursky. Socialist Fun: Youth, Consumption, and State-Sponsored Popular Culture in the Soviet Union, 1945-1970. Pittsburgh, PA: University of Pittsburgh Press, 2016. 366 pp. ISBN 978-0-8229-6396-7.
}

\begin{abstract}
Николай Митрохин - исследователь в Университете Восточной Финляндии (Йоэнсуу, Финляндия), научный сотрудник Центра восточноевропейских исследований (Forschungsstelle Osteuropa) в Университете Бремена (Германия). Адрес для переписки: Forschungsstelle Osteuropa an der Universität Bremen, Klagenfurter Straße 3, Bremen, 28359, Germany.mitrokhin@uni-bremen.de.
\end{abstract}

В последние два десятилетия среди отечественных и зарубежных историков устойчиво высок интерес к изучению советской молодежи в 1945-1970-е годы. Это обусловлено доступностью первичных (документы в бывших «комсомольских» архивах) и вторичных (художественные произведения, мемуары, опубликованные дневники) источников и сравнительной простотой интервьюирования пожилых людей, основная тема которого касается, вероятно, самого прекрасного периода их жизни. Книги о советской молодежи тех лет, студенчестве и вузах, оппозиционной активности молодых людей публикуются практически каждый год на русском и английском языках (Волчкевич 2009; Герасимова 2015; Димке 2018; Каримов 2004; Козлов и Мироненко 2005; Костырченко 2012; Мазус 2014; Митрохин 2003; Силина 2004; Fürst 2010; Hornsby 2013; Jones 2013; Roth-Ey 2011; Tromly 2014; Zubok 2009).

Работа Глеба Ципурского демонстрирует новую точку зрения в рамках этой широкой темы. Автор начинает свою книгу кратким пересказом сути одной из главных советских кинокомедий - «Карнавальной ночи», - и, собственно, весь его текст является обширным комментарием к зафиксированному в фильме «переломному моменту». Тогда, в середине 1950-х позднесталинская нормативная (но далекая от реальности) организация молодежного досуга в рамках жесткой идеологической индоктринации и принципиального отвержения всех западных новшеств в массовой культуре, целенаправленно сменялась моделью контролируемой сверху самодеятельности (с. 76-77) и избирательного привлечения адаптированной западной поп-культуры. Первое было следствием принципиального сдвига в комсомольской работе, когда от сформировавшейся в конце 1930-х годов системы жестких и постоянно менявшихся директивных указаний, исходящих от комсомольского «верха» «низам», комсомол по инициативе Никиты Хрущева после смерти Иосифа Сталина перешел к поощрению низовой активности (с. 102-103). Это, добавлю, сопровождалось реальной выборностью (не везде и не всегда, но во многих случаях) руководителей на уровне низовых организаций (вплоть до районных). Символом относительной свободы «молодежи» становится построенный на импровизации джаз, который в 1920-1950-е годы балансировал 
в СССР между периодами разрешений (и даже популяризации) и запретами, но во второй половине 1950-х получил окончательное одобрение «власти».

Таким образом, в центре работы Ципурского оказывается феномен художественной самодеятельности в СССР - самодеятельности, которая базировалась на системе «клубов» разных типов. Они создавались по настоянию партийных и комсомольских органов при производственных и учебных заведениях, а также как учреждения городского и местного самоуправления. Всего в СССР в 1953 году, согласно статистике, приведенной Ципурским, насчитывалось 123 тысячи клубов (с. 3). Основным вопросом работы является соотношение молодежного энтузиазма и «антизападного проекта альтернативной модернизации», чем, в представлении Ципурского, собственно, и был СССР как политический конструкт.

Молодежный энтузиазм, или «фан» (в риторике Ципурского), подразумевает самореализацию на основе обретения и трактовки актуального культурного продукта, пусть даже и имеющего источником скорее западное, чем отечественное, происхождение. И это сильный способ интеграции молодых поколений в существующий социум, который позволяет им реализовать свою энергию и креатив, нейтрализовать или минимизировать протестный потенциал в безопасных формах. Ведь нет ничего важнее для энергичных молодых людей, чем «борьба с дураками» в устоявшихся институциях, которая со временем благополучно заканчивается победой «умных» и «образованных», занимающих место «дураков» и продолжающих развивать и поддерживать систему уже за счет своих интеллектуальных ресурсов и социального капитала. Пока не придет их черед считаться «дураками» для следующих поколений, еще более «умных» и куда более «образованных».

В этом плане характерна победа советских «джазовых» людей, о которых пишет Ципурский и которые из нонконформистов 1950-х в 1970-е благополучно стали культурным истэблишментом. И с этим истеблишментом в свою очередь выходили бороться уже «рокеры». Но даже самые радикальные из них, скажем мы, стали ровно тем же культурным истэблишментом, порой весьма и весьма провластным, в 1990 -2000-е годы.

В этом контексте работа Ципурского противостоит популярнейшей работе Алексея Юрчака (Yurchak 2005). Если последний трактует освоение популярной западной культуры и углубление в нее как фактический отрыв от застывшего в своей индоктринации в ментальных 1930-х советского социума, - прорыв, ведущий к масштабным политическим последствиям, созданию пространства «пустоты» вокруг советской идеологической модели и полному краху последней, то Ципурский доказывает, что ограниченное освоение западной культуры и даже ирония в отношении устаревших советских культурных норм - вполне гармонировали с «советским» и модернизировали его. В этом отношении он дополняет рецензировавшуюся в Laboratorium работу Ольги Герасимовой (Митрохин 2017). Автор ее посвятила значительную часть текста разнообразным практикам культурного времяпрепровождения студентов МГУ, которые, при всем своем модернизме и даже «западничестве», никак не вели к их радикализации или обособлению от советского общества (Герасимова 2015). 
Однако тут, как и в случае с Герасимовой, возникает вопрос о том, какие аргументы для своих построений использует Ципурский, как сделана его книга? И некоторые сомнения появляются как при чтении общей концепции исследования, так и при изучении списка источников. Ципурский, как и многие другие авторы, пишущие о советской молодежи, оперирует понятием «поколение», которое распространяет на всю достигшую «молодежного» возраста когорту в позднесталинское или хрущевское время. При этом он берет для своего исследования примеры из жизни молодежи Москвы и Саратова - студентов университетов (в основном) и рабочих нескольких крупных фабрик (очень факультативно). Прямо скажем, подавляющее большинство его примеров касаются жизни студентов Саратовского университета, в дополнение приведены истории из жизни двух - трех московских информантов. Насколько объекты его исследования репрезентуют реальную «советскую молодежь», Ципурский не задумывается, что вызывает сожаление.

Очевидно, что описанные им группы являлись «передовыми» с точки зрения советской системы и вместе с тем представляли собой узкие сегменты соответствующей поколенческой когорты. Хотя автор пытается выстроить дистанцию между студентами Московского и Саратовского университетов, очевидно, что она в разы меньше, чем между типичным советским студентом и его сверстником из села. А дистанция между студентом университета и рабочим передового большого предприятия из крупного, преимущественно русского по этническому составу города в Европейской части СССР была куда меньше, чем между каждым из них и, например, западноукраинскими по происхождению студентами педагогического института в Галиции или не говорящими по-русски молодыми женщинами из кустарной артели где-нибудь в Узбекистане. Между тем в период исследуемой книги не менее половины населения страны еще проживала в селах, а из номинальных горожан многие обитали - в небольших населенных пунктах с полусельским бытом. Более того, примерно половина возрастной когорты в середине 1950-х (а ранее, в 1930-х, и вовсе 90\% - о чем Ципурский пишет и сам) не были членами ВЛКСМ и идеологической индоктринации комсомола или клубов предпочитали, видимо, иные формы самовыражения и развлечения. Деревенские гармонисты, «блатняк» под гитару, прослушивание западных «голосов», религиозные собрания и паломничества, нормы поведения, основанные на «адате» и других нормах патриархального права, частные вечеринки и просто энергичное употребление алкоголя и беспорядочный секс были вполне себе нормой культурного потребления и времяпрепровождения, куда более важной для огромных категорий молодежи (в отличие от сравнительно немногочисленных и подробно описанных в тексте «альтернативных» официальному дискурсу стиляг).

И здесь встает вопрос о том, в какой степени описываемая система клубов и «фана» была релевантна возрастной когорте? Точнее, с учетом достаточно продолжительного периода, который охватывает исследование (1945-1970 гг.), - когортам? Кого она, собственно, инициировала на вхождение в «систему» и почему? В частности любопытен вопрос о том, соответствует ли действительности приведенное Ципурским количество клубов в 123 тысячи? Можно ли в самом деле описывать средний советский клуб как помещение из двух залов для лекций, темати- 
ческих классов для занятий и даже столовой, как это утверждает автор во введении, если по приводимым им же данным в среднем в одном клубе было менее трех «кружков» (324 тысячи на 1953 г. (с. 45))? Или же в действительности одни из них не существовали вовсе, а вторые представляли собой избы или малоприспособленные бараки, и лишь третьи, при мощных предприятиях, «колхозахмиллионерах» или при райисполкомах крупных городов, находились в специально построенных зданиях? Возможно, именно их («городские» клубы, составлявшие, согласно приводимой автором статистике, чуть более 8\% от всех клубов страны (10 050 на тот же 1953 год, см. с. 33)) Ципурский имеет в виду, рассказывая нам о клубной самодеятельности? В остальных же дело ограничивалось показом фильмов, скудной по книжному ассортименту «ленинской комнатой» (или вовсе книжным шкафом) вместо библиотеки, танцами по выходным да одним кружком или спортивной секцией, в которых принимали участие 10-15 человек, то есть в лучшем случае двадцатая часть «молодежи» усредненного села.

Какая часть «советской молодежи» - то есть соответствующей возрастной когорты - реально, а не на бумаге, принимала участие в подобной деятельности и тем более «творчески» участвовала в оной? А какая часть не принимала, причем по идейным соображениям, и свои творческие порывы и оформленные культурные предпочтения реализовывала другими способами?

На практике в тексте Ципурский без всяких оговорок приравнивает почти 5 миллионов участников художественной самодеятельности (данные на 1953 год) к молодежи (с. 45), не учитывая того факта, что эти люди могли быть «бумажной армией» фальшивых отчетов или не входить в рассматриваемую возрастную категорию. Так, приводя пример самодеятельного ансамбля братьев Кравченко из Одессы, активно используемый в советской внешнеполитической пропаганде, автор не обращает внимания на то, что на фото этого коллектива изображены люди, которым очевидно 40-60 лет (с. 80-81). В том же абзаце он делает еще одно генерализирующее утверждение, заявляя, что все эти люди испытывали такие же восторженные эмоции, как и несколько опрошенных им бывших саратовских комсомольских функционеров. И хотя позже он деконструирует тот же тезис, рассказывая, что некоторым навязчивая пропаганда не нравилась или даже вызывала смех (с. 47-48), дальше фиксации подобных настроений он не уходит. А ведь часть участников самодеятельности могла, не переходя к подробно рассматриваемым Ципурским далее образцам западной культуры, проникающим в советский социум, пользуясь абсолютно «ортодоксальными» советскими пропагандистскими формами, вкладывать в нее свои совершенно не советские чувства и эмоции: от желания завязать отношения с другим участником или руководителем коллектива (как например, в фильме «Деревенский детектив» 1968 года) до своего рода ухищрения, когда под видом одобряемого государством народного творчества старались сохранять и развивать национальную (этническую) и даже религиозную культуру. Между тем популярность хоровых и танцевальных коллективов в республиках Прибалтики, породившая в итоге феномен «поющих наций», а в конечном счете и «Народные фронты» (Christophe 1997; Muiznieks 1997; Taagepera 1993), позволяет говорить о том, что реальная самодеятельность во многих случа- 
ях была далека от комсомольского энтузиазма и идеологии, во всяком случае в том виде, в котором она была распространена в центральной России.

В результате Ципурский в третьей части работы, говоря о позднесталинском времени, переходит к простой дихотомии, противопоставляя господствующей в культуре «клубов» пропаганде историю развития джаза и западных танцев (и борьбы с ними). Почему из множества идеологических кампаний конца 1940-х начала 1950-х годов были избраны именно они, а не, например, кампании по борьбе с национализмом (в том числе в сфере музыки), формализмом или с литературой (как, например, борьба с символизмом Анны Ахматовой, юмором Михаила Зощенко и прочее), которые также активно затрагивали репертуар творческих коллективов, - автор не объясняет. Однако надо сказать, что про джаз автор рассказывает подробно, со знанием дела (если не сказать - с любовью), на восьми страницах (с. 57-65). Что особенно заметно на фоне тех двух страниц, которые отведены такому не менее распространенному явлению, каковым были танцы в западном стиле.

Вместе с тем автор совершенно верно обращает внимание на то, что многие пропагандистские инициативы упирались в простой факт: на низовом уровне и устроители массовых мероприятий, и их контролеры игнорировали кампании в силу своих собственных базовых интересов. Директорам домов культуры, клубов и прочих культурных учреждений надо было выполнять финансовый план, за который с них спрашивали куда строже, чем за идеологический пуризм. И в том, что касается наполнения кассы, западные танцы и фильмы были незаменимы. Местным же контролерам, прежде всего комсомольским деятелям, было ни к чему устраивать слишком уж большие скандалы на работе и месте учебы, что грозило не только конфликтами со сверстниками, но и возможными неприятностями с начальством (с. 67-70).

В целом разобравшись с мотивами участия в художественой самодеятельности (и джазе) в первой трети своей работы, две оставшиеся трети (порядка 140 страниц) Ципурский посвящает беглому обзору бурных изменений, произошедших в данной сфере в период после смерти Сталина вплоть до 1970-го года.

Его особое внимание привлекает система молодежных самодеятельных клубов, которая стала заметным новшеством хрущевского времени. То есть параллельно с клубами как «учреждениями», выполнявшими функции «площадок» для запланированной творческой и развлекательной активности, стали возникать «клубы» единомышленников, пользующихся любыми помещениями для организации интересной им политической, культурной или научной активности. На 1967 год, по официальной статистике, таких в стране насчитывалось двенадцать тысяч, а общее число их участников доходило до одного миллиона человек (с. 110). 0pганизация подобных клубов вела к появлению независимых центров комсомольской и пионерской активности (Димке 2018), которые, пережив расцвет в 1960-е, медленно затухали в 1970-1980-е годы.

Другим важным аспектом исследования является стремительная модернизация репертуара молодежных коллективов. Последнее произошло в том числе в результате Всемирного фестиваля молодежи и студентов в Москве в 1957 году. 
Назвать данный процесс вестернизацией трудно, поскольку предыдущие, одобряемые идеологией позднесталинского времени, формы (например, в танцевальной культуре вальс или строгие костюмы на артистах) являлись начетническим повторением форм все той же европейской культуры начала XX века. Тем не менее возникновение молодежных кафе, претендующих на современный западный шик (с. 173-177) и внедрение других западных «штучек» в повседневную жизнь создавали у молодежи крупных городов (которую Ципурский предпочитает именовать «советской молодежью») иллюзию прогресса.

В целом подобный обзор тенденций (и отчасти событий), насыщенный разумным количеством статистики, безусловно полезен для студентов и аспирантов, впрочем, отдельные замечания в нем могут порадовать и специалистов.

Книга Ципурского похожа на реинкарнацию «Карнавальной ночи» в виде сериала «0ттепель». Молодежь 1960-х предстает не в ватнике на целине, стройке или в цеху, не с фиксой во рту и кепарем на затылке, не в городском восстании в Александрове, Краснодаре, Нальчике или Чимкенте (ни о чем из перечисленного в книге не сказано ни слова), а гламурной тусовкой комсомольских энтузиастов, перемещающихся между студенческой аудиторией, молодежным кафе и джазовым концертом в доме культуры электролампового завода.

Если искать в работе позитивные моменты и дополнять (из головы) недостающие крупные фрагменты в описании популярных у молодежи той эпохи занятий, то можно констатировать, что книга Ципурского дает наглядное представление о том, что советская молодежь из крупных городов исследуемого периода при некоторых (порой - весьма существенных) идеологических ограничениях имела значительный выбор возможностей для социализации. Это могло происходить как в желаемых КПСС и государством формах идеологической индоктринации и коллективного действия, так и в различных режимах самореализации. Среди них были форматы, включенные в официальную парадигму допустимого, запланированные и финансируемые, но в целом аполитичные (кружки, спортивные секции и клубы по интересам). Были объединения пользующиеся государственной инфраструктурой, но скрыто-фрондерские, такие, например, как джаз и КСП-клубы, студенческие театры, группы и организации защитников природы и памятников архитектуры. Не финансировались и не пользовались инфраструктурой, но носили легальный характер такие формы группового самовыражения как дружеские компании, например (см. с. 112-113), или художественное творчество и спортивные состязания круга единомышленников в коллективе - например, «оригинальное» празднование профессиональных и государственных праздников с коллегами, туристические походы. Между тем были форматы и в большей или меньшей степени, порицаемые и преследуемые - от групп, реализующих свою сексуальность или интерес к моде и западной современной музыке до криминальных, религиозных, этнонационалистических, «андеграундных» или диссидентских организаций.

Разумеется, рядовой представитель молодежи не имел физической возможности воспользоваться всеми этими вариантами, тем более абсолютно свободно, поскольку распределены они были в СССР неравномерно, информационный обмен был существенно ограничен, а наказание за переход зачастую незримых границ 
между одобряемым и легальным к наказуемому и нелегальному угрожало всегда, однако похожие проблемы были у их сверстников в любой стране мира. Чтобы стать «своим» в студенческих братствах Оксфорда, среди байкеров Техаса или активистов «Черных пантер» в Филадельфии, надо иметь, помимо желания, определенные финансовые и технические возможности и комплекс серьезных и признаваемых сообществом аргументов, пройти процедуру инициации. Кроме того, нужно быть готовым к тому, что государство накажет за точное соблюдение правил, принятых в сообществах, но нарушающих законодательство, или просто за членство в том или ином сообществе, если эта группа будет признана криминальной.

Отсюда проистекает ряд вопросов, выходящих далеко за пределы рецензируемой работы. Какие модели поведения, культурного потребления и самореализации были характерны для представителей всего спектра групп молодежи в советском социуме, а не только для русскоязычных комсомольцев крупных городов? Можно ли вообще говорить об обобщенной «советской молодежи» и каков набор идеологических и культурных символов, который в этот период делал ее таковой? Каково влияние на этот процесс (и в чем именно оно сказывалось) стремительного повышения образовательного уровня молодежи, пережившей как раз в 19501960-е годы переход к полному среднему образованию, и резкого увеличения количества людей с высшим образованием и студентов? Какую роль оказывала стремительная урбанизация и миграция в крупные города и освоение городского центра мигрантами и жителями ранее безнадежно «бескультурных» окраин? В чем сходство и отличие этой молодежи от «усредненных» сверстников в странах «социалистического» и «капиталистического» лагерей и странах третьего мира?

Для ответов на вышеперечисленные вопросы, тем не менее, нам небходимо дождаться исследований, анализирующих не только «комсомольский» и «диссидентский» городской молодежный социум этого периода, но и более массовые слои молодых горожан, жителей посада (частных домовладений в городах и пригородных поселках), села и деревни, этнически и религиозно обособленных традиционалистских общин и различных специфических (в том числе в профессиональном отношении, как, например, кадровые военные) групп советского общества.

\section{СПИСОК ЛИТЕРАТУРЫ}

Волчкевич, Илья. 2009. Сословие вольных людей: книга о Бауманском и бауманцах. Т. 2, Признание школы. М.: Рубежи XXI.

Герасимова, Ольга. 2015. «Оттепель», «заморозки» и студенты Московского университета. М.: АИРО-XX век.

Димке, Дарья. 2018. Незабываемое будущее. Советская педагогическая утопия 1960-х. М.: Common place.

Каримов, Игорь. 2004. История Московского КСП. М.: Янус-К.

Козлов, Владимир и Сергей Мироненко, ред. 2005. Крамола. Инакомыслие в СССР при Хрущеве и Брежневе (1953-1982). М.: Материк.

Костырченко, Геннадий. 2012. Тайная политика Хрущева: власть, интеллигенция и еврейский вопрос. М.: Международные отношения.

Мазус, Израиль, сост. 2014. Подпольные молодежные организации, группы и кружки (19261953 гг.). К истории молодежного сопротивления большевизму. Справочник. М.: «Возвращение», Государственный музей ГУЛАГа. 
Митрохин, Николай. 2003. Русская партия: движение русских националистов в СССР 19531985 гг. М.: НЛО.

Митрохин, Николай. 2017. Рецензия на «Оттепель», «заморозки» и студенты Московского университета, Ольга Герасимова. Laboratorium: журнал социальных исследований 9(2):183-192.

Силина, Лада. 2004. Настроения советского студенчества. М.: Русский мир.

Christophe, Barbara. 1997. Staat versus Identität: Zur Konstruktion von "Nation" und "nationalen Interesse" in den litauischen Transformationsdiskursen von 1987 bis 1995. Cologne: Verlag Wissenschaft und Politik.

Fürst, Juliane. 2010. Stalin's Last Generation: Soviet Post-War Youth and The Emergence of Mature Socialism. 0xford: 0xford University Press.

Hornsby, Robert. 2013. Protest, Reform and Repression in Khrushchev's Soviet Union. Cambridge: Cambridge University Press.

Jones, Polly. 2013. Myth, Memory, Trauma: Rethinking the Stalinist Past in the Soviet Union, 19531970. New Haven, CT: Yale University Press.

Muiznieks, Nils. 1997. “Latvia: Restoring a State, Rebuilding a Nation." Pp. 376-397 in New States, New Politics: Building the Post-Soviet Nations, edited by Ian Bremmer and Ray Taras. New York: Cambridge University Press.

Roth-Ey, Kristin. 2011. Moscow Prime Time: How the Soviet Union Built the Media Empire That Lost the Cultural Cold War. Ithaca, NY: Cornell University Press.

Taagepera, Rein. 1993. Estonia: Return to Independence. Boulder, C0: Westview Press.

Tromly, Benjamin. 2014. Making the Soviet Intelligentsia: Universities and Intellectual Life under Stalin and Khrushchev. Cambridge: Cambridge University Press.

Yurchak, Alexei. 2005. Everything Was Forever, Until It Was No More: The Last Soviet Generation. Princeton, NJ: Princeton University Press.

Zubok, Vladislav. 2009. Zhivago's Children: The Last Russian Intelligentsia. Cambridge, MA: Harvard University Press. 